\title{
Dimensões do empoderamento feminino no Brasil: índices e caracterização por atributos locacionais e individuais e participação no Programa Bolsa Família
}

\author{
Maria Carolina do Amaral Couto* \\ Carlos César Santejo Saiani ${ }^{\star \star}$
}

\begin{abstract}
A superação de desigualdades de gênero em uma sociedade com fortes bases patriarcais, como a brasileira, tem como um de seus elementos centrais o empoderamento feminino. Diante da sua importância para a transformação do papel social da mulher, é fundamental que se discutam ações de promoção, fortalecimento e mensuração. Para subsidiar tal debate, vem ganhando destaque na literatura a construção de índices sintéticos de empoderamento, o que ainda é pouco explorado no Brasil. Este estudo contribui para o preenchimento desta lacuna. Utilizando dados da Pesquisa Nacional de Demografia e Saúde da Criança e da Mulher de 2006, os objetivos foram: propor e calcular dois índices sintéticos de empoderamento feminino, que refletem dimensões econômicas, domésticas e psicológicas; e, com estes índices, caracterizar a situação no Brasil segundo atributos locacionais e individuais e participação no Programa Bolsa Família (PBF). As evidências sugerem um caráter multidimensional do empoderamento, a importância do trabalho e de outros atributos individuais e locacionais e possíveis efeitos do PBF em dimensões econômicas e domésticas do empoderamento de suas beneficiárias.
\end{abstract}

Palavras-chave: Empoderamento feminino. Índices. Programa Bolsa Família.

\footnotetext{
* Universidade Federal de Uberlândia (UFU), Uberlândia-MG, Brasil (maria_carolinaac@hotmail.com; https://orcid. org/0000-0002-5869-2041).

** Instituto de Economia e Relações Internacionais, Universidade Federal de Uberlândia (UFU), Uberlândia-MG, Brasil (ssaiani@ufu.br; https://orcid.org/0000-0002-4205-1514).
} 


\section{Introdução}

Os dados de violência doméstica, a menor remuneração e a forma de inserção no mercado de trabalho, a divisão desigual dos afazeres domésticos e a sub-representação política, entre outros aspectos, refletem um cenário pessimista para as mulheres brasileiras. Para superar tais problemas, um elemento central é o empoderamento feminino, entendido como um processo multidimensional de transformação do papel social da mulher, que deixa de ser subordinada aos homens e passa a figurar como um agente atuante, capaz e com poder de tomar decisões pessoais e coletivas (ROWLANDS, 1995; LEÓN, 2001).

Devido a essa importância, é necessário que estratégias de promoção e mensuração do empoderamento e de avaliação de seus possíveis condicionantes sejam planejadas e executadas, o que justifica e motiva este estudo. Uma alternativa metodológica para calcular conceitos sociais abstratos, como o empoderamento, é a construção de índices sintéticos, que possibilitam quantificar e sumarizar várias dimensões em uma única medida (JANNUZZI, 2006).

Na literatura, há trabalhos que apresentam índices sintéticos de empoderamento feminino para diferentes países, mas existe uma aparente lacuna para o caso brasileiro, ${ }^{1}$ que se deve, ao menos em parte, à escassez de dados representativos e periódicos. Nesse contexto, o presente estudo contribui para o preenchimento dessa lacuna na literatura ao cumprir dois objetivos: propor e calcular índices sintéticos para dimensões do empoderamento feminino no Brasil; e, com estes, caracterizar a situação do empoderamento feminino no país segundo atributos locacionais e pessoais e o status de participação no Programa Bolsa Família (PBF).

Os parâmetros de caracterização foram escolhidos para garantir, a partir dos índices calculados, evidências adicionais ao debate sobre condicionantes do empoderamento feminino. A seleção dos atributos locacionais e pessoais respeita a existência de dados e segue a literatura, que também discute efeitos do PBF. Assim, uma hipótese implícita às análises é a de que uma política pública - no caso, um dos maiores programas de transferências condicionais de renda e com pagamento prioritário às mulheres -, ao possibilitar condições para um maior apoio e fortalecimento das mulheres, catalisa (não origina) o empoderamento (BERTH, 2019).

São construídos dois índices sintéticos de empoderamento feminino: um para dimensões econômicas e domésticas; e outro relativo à percepção quanto ao consenso em relações sexuais. 0 primeiro capta a dinâmica familiar das mulheres, refletida na capacidade de tomar decisões pessoais e familiares, financeiras ou não, e o segundo sinaliza o entendimento da própria mulher sobre o direito de negar relações sexuais com o companheiro em variados cenários.

\footnotetext{
${ }_{1}^{1}$ Porém, são calculados índices de (des)igualdade de gênero, como em Souza (2012) e Bortoluzzo et al. (2016).
} 
Os dados para os cálculos dos índices (e atributos) são oriundos da Pesquisa Nacional de Demografia e Saúde da Criança e da Mulher (PNDS) de 2006, única base encontrada com as informações necessárias e uma amostra representativa para todo o país. Apesar de as informações da PNDS estarem relativamente defasadas, é plausível supor que alterações significativas nos padrões observados são lentas e dependentes de transformações culturais, sociais e legais que, per se, demandam tempo para serem efetivadas. Além disso, as evidências deste estudo podem estruturar comparações com uma nova PNDS, prevista para os próximos anos.

Além dessa introdução e das considerações finais, o estudo é composto por outras três seções. A seguir é feita uma breve revisão sobre conceituação e mensuração do empoderamento feminino. Posteriormente apresentam-se os dados e os parâmetros para o cálculo dos índices e, finalmente, é caracterizado o empoderamento feminino brasileiro segundo os índices calculados e os atributos escolhidos.

\section{Empoderamento feminino: breve revisão da literatura}

A desigualdade de gênero no Brasil é sedimentada em um sistema social patriarcal, herdado do período colonial, no qual os homens têm o poder e ditam as normas que regem as atividades coletivas e individuais (DELPHY, 2009). Tal estrutura condiciona os indivíduos a desempenharem certos papéis, destinando à mulher a situação de subordinação, que se perpetua por diversos espaços sociais, como família, religião e política (BASTOS et al., 2018). Por uma perspectiva feminista, o empoderamento é um dos elementos fundamentais para superar a subordinação feminina e alcançar a equidade de gênero (LISBOA, 2008).

Batliwala (1997) destaca que o termo empoderamento contém, em si, a palavra poder, que pode ser entendido como o controle sobre recursos materiais, intelectuais e ideológicos. 0 poder pertence a quem influencia a distribuição e aplicação destes recursos, sendo que quanto maior a quantidade controlada, maior é o poder do indivíduo (ou grupo). Logo, o empoderamento feminino pode ser compreendido como um desafio às relações de poder existentes e, mais do que isso, um esforço para obter maior controle sobre as fontes deste poder.

Rowlands (1995) ressalta a importância de considerar gênero, cor e outras formas de opressão em análises da distribuição do poder na sociedade. A autora evidencia também que o poder é tradicionalmente interpretado como uma relação de obediência e, se analisado sob a vertente de gênero, é comum se dar das mulheres em relação aos homens. Assim, é um instrumento de dominação que pode ser usado para interferir nos mais diversos aspectos da vida das mulheres.

Ademais, o empoderamento pode ser entendido como um processo multidimensional (ROWLANDS, 1995; BATLIWALA, 1997; LEÓN, 2001), além de não linear, contextual e heterogêneo. Tal processo pode ser distinto entre as mulheres (ou grupos de mulheres), segundo suas experiências de vida e seus contextos cultural, histórico e socioeconômico (LEÓN, 2001). 
Defende-se, ainda, que o processo deve suscitar do próprio grupo e não pode ser “dado" às mulheres por outro agente. Assim, uma política pública, como o PBF, não é a origem do empoderamento, mas pode agir como catalisadora, criando ambiente de apoio e fortalecimento feminino (BERTH, 2019). Indispensável complementar que o empoderamento tem importantes aspectos individuais, como o processo de tomada de consciência, autonomia e autoestima, mas é indissociável de um processo coletivo que promova transformações no papel social da mulher a nível estrutural (ROWLANDS, 1995; BATLIWALA, 1995; LEÓN, 2001; BERTH, 2019).

Além da demarcação conceitual, há um movimento do feminismo acadêmico para tornar o conceito mais analítico e metodológico com a segmentação em categorias, segundo as quais o empoderamento se concretiza (LEÓN, 2001). Por exemplo: Rowlands (1995) estabelece três dimensões (pessoal, relacionamentos e coletivo); Stromquist (1997) define quatro componentes (cognitivo, político, psicológico e econômico) e dois níveis (micro e macro); Alsop et al. (2007) adotam três domínios (Estado, mercado e sociedade) e três níveis (local, macro e intermediário); e Mageste et al. (2008) apontam três níveis (individual, relacional e contextual).

Todas as categorizações abrangem diversos aspectos da vida da mulher, partindo de subjetivos e individuais até objetivos e estruturais. Isso é embasado e, ao mesmo tempo, reforça o argumento do empoderamento como um fenômeno multidimensional que não ocorre apenas a nível individual, mas, necessariamente, também se relaciona a aspectos estruturais associados a questões de gênero. Com base nessa discussão e para embasar os índices aqui calculados, é proposta a sistematização pela tipologia de quatro dimensões e três níveis de análise apresentada no Quadro 1, que também traz exemplos provenientes da interseção entre as dimensões e os níveis.

0 nível individual diz respeito às relações interpessoais da mulher com filhos, cônjuges, parentes, amigos, etc. 0 intermediário ultrapassa os limites das relações cotidianas, mas abaixo do nível nacional. 0 estrutural é aquele que já alcançou o nacional, com possibilidade de causar transformações a nível global.

O movimento em direção à categorização e ao maior poder analítico do conceito resultou em trabalhos que constroem índices sintéticos de empoderamento feminino. 0 Quadro 2 reporta os trabalhos encontrados com índices calculados com medidas diretas ${ }^{2}$ para diferentes locais do mundo, mas com certo viés geográfico para o Sul Asiático (ASSAAD et al., 2014). ${ }^{3}$ Uma discussão detalhada sobre cada trabalho do Quadro 2 foge do escopo deste estudo, mas se destaca a recorrência das dimensões econômicas e domésticas aqui

\footnotetext{
${ }^{2}$ No geral, as medidas indiretas utilizadas como proxies do empoderamento feminino são baseadas na escolaridade e no trabalho. Já as medidas diretas são derivadas de perguntas feitas às mulheres quanto a suas percepções e capacidades de participação nas decisões de vários aspectos da sua vida (MASON; SMITH, 2003; ASSAAD et al., 2014).

${ }^{3}$ As dimensões do Quadro 2 são expostas segundo o referencial teórico e as apresentações dos índices dos próprios trabalhos e não conforme a tipologia do Quadro 1.
} 
também adotadas. Ademais, não foi observado um trabalho que desenvolva um índice nestes moldes para o Brasil. ${ }^{4}$

QUADRO 1

Dimensões e níveis do empoderamento feminino

\begin{tabular}{|c|c|c|c|}
\hline \multirow{2}{*}{ Dimensões } & \multicolumn{3}{|c|}{ Níveis } \\
\hline & Individual & Intermediário & Estrutural \\
\hline Psicológica & $\begin{array}{l}\text { Autoestima; tomada de } \\
\text { consciência }\end{array}$ & $\begin{array}{l}\text { Consciência coletiva do papel } \\
\text { de subordinação da mulher na } \\
\text { sociedade }\end{array}$ & $\begin{array}{l}\text { Superação da ideia de } \\
\text { inferioridade feminina; } \\
\text { exposição positiva da mulher } \\
\text { em meios de comunicação }\end{array}$ \\
\hline Doméstica & $\begin{array}{l}\text { Participação no processo } \\
\text { decisório de questões } \\
\text { familiares; ausência de } \\
\text { violência doméstica ou } \\
\text { qualquer tipo de repressão } \\
\text { nas relações interpessoais }\end{array}$ & $\begin{array}{l}\text { Campanhas massivas contra a } \\
\text { violência doméstica }\end{array}$ & $\begin{array}{l}\text { Transformação dos padrões de } \\
\text { divisão do trabalho doméstico }\end{array}$ \\
\hline Econômica & $\begin{array}{l}\text { Participação nos desembolsos } \\
\text { financeiros da família; } \\
\text { autonomia para participar do } \\
\text { mercado de trabalho; controle } \\
\text { de seu próprio dinheiro }\end{array}$ & $\begin{array}{l}\text { Acesso a crédito; posse de } \\
\text { bens ou terras }\end{array}$ & $\begin{array}{l}\text { Pagamento de salários } \\
\text { equitativos entre homens e } \\
\text { mulheres }\end{array}$ \\
\hline Político-legal & $\begin{array}{l}\text { Conhecimento de direitos e } \\
\text { deveres; autonomia para votar } \\
\text { e ter preferências políticas } \\
\text { particulares }\end{array}$ & $\begin{array}{l}\text { Possibilidade de mobilização } \\
\text { local pela luta de direitos } \\
\text { ou campanhas de } \\
\text { conscientização }\end{array}$ & $\begin{array}{l}\text { Participação efetiva da mulher } \\
\text { em todas as esferas de } \\
\text { governo }\end{array}$ \\
\hline
\end{tabular}

Fonte: Rowlands (1995), Stromquist (1997), Alsop et al. (2007) e Mageste et al. (2008). Elaboração dos autores.

QUADRO 2

Síntese dos trabalhos com índices sintéticos de empoderamento: dimensões

\begin{tabular}{|c|c|c|}
\hline Trabalhos & Dimensões & Delimitação geográfica \\
\hline Malhotra e Mather (1997) & Econômica, social e organizacional & Sri Lanka \\
\hline Jejeebhoy e Sathar (2001) & Econômica, mobilidade e liberdade de ameaças & Paquistão e Índia \\
\hline Mason e Smith (2003) & Econômica, reprodutiva, mobilidade e violência & $\begin{array}{l}\text { Índia, Malásia, Paquistão, } \\
\text { Filipinas e Tailândia }\end{array}$ \\
\hline Al Riyami et al. (2004) & Econômica, doméstica e mobilidade & Omã \\
\hline Gupta e Yesudian (2006) & $\begin{array}{l}\text { Doméstica, econômica, mobilidade, atitude em } \\
\text { relação à igualdade de gêneros e à violência } \\
\text { doméstica }\end{array}$ & Índia \\
\hline Haque et al. (2011) & Econômica, doméstica e mobilidade & Bangladesh \\
\hline Khan e Awan (2011) & Doméstica e econômica & Paquistão \\
\hline Varghese (2011) & Doméstica, social, econômica e legal & Omã \\
\hline Do e Kurimoto (2012) & $\begin{array}{l}\text { Econômica, doméstica, saúde, reprodutiva, } \\
\text { sexual e violência }\end{array}$ & $\begin{array}{l}\text { Namíbia, Zâmbia, Gana e } \\
\text { Uganda }\end{array}$ \\
\hline Assaad et al. (2014) & Econômica, doméstica e mobilidade & Egito \\
\hline Islam et al. (2014) & Doméstica & Bangladesh \\
\hline Phan (2015) & $\begin{array}{l}\text { Trabalho, econômica, doméstica, mobilidade, } \\
\text { educação e reprodutiva }\end{array}$ & $\begin{array}{l}\text { Camboja, Indonésia, Filipinas e } \\
\text { Timor-Leste }\end{array}$ \\
\hline Arestoff e Djemai (2016) & Atitude em relação à violência doméstica & $\begin{array}{l}\text { Etiópia, Malawi, Ruanda, } \\
\text { Uganda e Zimbábue }\end{array}$ \\
\hline Ewerling et al. (2017) & $\begin{array}{l}\text { Atitude em relação à violência, independência } \\
\text { social, econômica e doméstica }\end{array}$ & 34 países da África \\
\hline
\end{tabular}

Fonte: Malhotra e Mather (1997), Jejeebhoy e Sathar (2001), Mason e Smith (2003), Al Riyami et al. (2004), Gupta e Yesudian (2006), Haque et al. (2011), Khan e Awan (2011), Varghese (2011), Do e Kurimoto (2012), Assaad et al. (2014), Islam et al. (2014), Phan (2015), Arestoff e Djemai (2016), Ewerling et al. (2017). Elaboração dos autores.

\footnotetext{
${ }^{4}$ Além de trabalhos científicos, organizações internacionais também calculam indicadores de empoderamento feminino (ou de equidade de gênero) para países, inclusive o Brasil - não sendo possível fazer desagregações como as das análises mais adiante. Soares (2013) revisa os principais índices de organizações internacionais.
} 


\section{Índices de empoderamento feminino para o Brasil}

Fundamentando-se na revisão da seção anterior, são aqui propostos índices sintéticos de empoderamento feminino para o Brasil. A única base com os dados necessários é a Pesquisa Nacional de Demografia e Saúde da Criança e da Mulher (PNDS) de 2006. Análises com dados de 2006 talvez não representem perfeitamente a realidade recente do país, mas é plausível supor que, no geral, alterações nos padrões observados sejam graduais e demandam tempo, dependendo de transformações culturais, sociais e legais que, per se, também são demoradas.

A PNDS é oriunda do programa The Demographic and Health Surveys (DHS) da Agência dos Estados Unidos (EUA) para o Desenvolvimento Internacional (USAID), em parceria com organizações internacionais, como o Fundo das Nações Unidas para a Infância (Unicef) e o Banco Mundial. 0 objetivo do DHS é fornecer assistência técnica a pesquisas, promovendo a compreensão de tendências de saúde, nutrição e demográfica nos países em desenvolvimento.

Dados de pesquisas promovidas pelo programa DHS são bastante usados na construção de índices sintéticos de empoderamento feminino. São os casos de Gupta e Yesudian (2006), Do e Kurimoto (2012), Arestoff e Djemai (2016) e Ewerling et al. (2017), apresentados no Quadro 2. Raj (2017) destaca a importância destes dados e dos índices derivados, mas também aponta limitações, como ausência de informações relevantes e inconsistências entre os países.

O Brasil participou de três fases do programa DHS, sendo que a última gerou a PNDS de 2006. A representatividade desta pesquisa é nacional, abarcando áreas urbanas e rurais e as cinco macrorregiões, com informações referentes a 15.575 mulheres de 15 a 49 anos. A coleta dos dados se deu por dois questionários, um respondido pelo responsável do domicílio, com variáveis socioeconômicas dos domicílios e moradores, e o outro pelas mulheres, com variáveis relacionadas a elas e aos filhos de até cinco anos. 0 questionário da mulher é composto pelas seções: características da entrevistada; reprodução; anticoncepção e acesso a medicamento; gravidez e parto; conjugalidade e atividade sexual; planejamento da fecundidade; atributos do cônjuge e do trabalho; mensurações antropométricas; e coleta de sangue.

Baseando-se nos trabalhos do Quadro 2 e restringindo-se aos dados disponíveis na PNDS, são aqui calculados dois índices sintéticos de empoderamento feminino. 0 primeiro é o índice econômico e doméstico (ED), construído a partir de questões que captam a dinâmica familiar das mulheres e suas capacidades de influenciar decisões pessoais e familiares. O segundo é o índice de percepção quanto ao consenso em uma relação sexual (PCRS), que se refere ao entendimento da entrevistada sobre a possibilidade de uma mulher negar relações sexuais com o companheiro em diversos cenários, inclusive se simplesmente não desejar. 
Considerando a tipologia aqui proposta (Quadro 1), é plausível alinhar o índice ED ao nível individual e às dimensões domésticas e econômicas, pois capta a capacidade de a mulher influenciar decisões familiares, incluindo aquelas relacionadas a dispêndios financeiros. 0 índice PCRS associa-se ao nível individual e à dimensão psicológica, refletindo a compreensão da mulher quanto ao poder sobre seu corpo e suas vontades em relações íntimas.

As perguntas da PNDS usadas nos cálculos dos índices constam no Quadro 3. A escolha destas é fundamentada pelos trabalhos apresentados no Quadro 2. Não há consenso quanto ao processo de decisão: alguns consideram apenas se a mulher decide sozinha, descartando como empoderadas se decidirem com cônjuges ou outras pessoas (AL RIYAMI et al., 2004; DE BRAUW et al., 2014); enquanto outros não diferenciam decisões isoladas e conjuntas (GUPTA; YESUDIAN, 2006; DO; KURIMOTO, 2012; ISLAM et al., 2014). Há, ainda, trabalhos que fazem distinções por pesos, atribuindo valor máximo se a mulher decide sozinha, valor inferior se a decisão é compartilhada e zero se a mulher não se envolver na decisão (JEJEEBHOY; SATHAR, 2001; ASSAD et al., 2014; PHAN, 2015; EWERLING et al., 2017). ${ }^{5}$ Este estudo segue a última linha para a construção do índice ED: é atribuído peso dois em cada pergunta para as mulheres que decidem sozinha; peso um para aquelas que compartilham a decisão; e peso nulo para as que não participam da decisão (Quadro 3). Assim, considerando as perguntas e os pesos, o índice ED tem valor mínimo zero e máximo 12.

No índice PCRS, seguindo a literatura discutida anteriormente, entende-se que a mulher consciente de sua capacidade de tomar decisões autônomas que envolvam suas vontades e seu corpo deve expressar a possibilidade de negar uma relação sexual por um motivo aparente, como ter tido um filho recentemente, e sem motivo, se não desejar. Analogamente a Gupta e Yesudian (2006), a ideia subjacente ao índice PCRS é a aceitação ou não de supostas normas sociais que "garantem" aos homens o "direito" a relações sexuais, mesmo se as companheiras não estiverem dispostas. Em cada pergunta, é atribuído o peso um às mulheres com respostas positivas e zero para aquelas com respostas negativas ou que não sabem. Como são consideradas cinco perguntas, o valor do índice varia entre zero e cinco.

\footnotetext{
${ }^{5}$ Há também formas híbridas, como em Haque et al. (2011), que partem de definições distintas para empoderamento e autonomia, o que interfere na construção de seus índices: para a autonomia, é considerado se a mulher decide sozinha; já para o empoderamento, também se a decisão é compartilhada.
} 
QUADRO 3

Perguntas da PNDS para a construção dos dois índices de empoderamento feminino e pesos

\begin{tabular}{|c|c|c|c|c|c|}
\hline Índices & Perguntas & Respostas & Pesos & $\begin{array}{c}\text { Peso } \\
\text { mínimo }\end{array}$ & $\begin{array}{c}\text { Peso } \\
\text { máximo }\end{array}$ \\
\hline \multirow[b]{2}{*}{$\begin{array}{l}\text { Econômico e } \\
\text { doméstico } \\
\text { (ED) }\end{array}$} & $\begin{array}{l}\text { Quem decide/decidia o que fazer } \\
\text { com o dinheiro que você ganha/ } \\
\text { ganhava? }\end{array}$ & $\begin{array}{l}1 \text { - entrevistada } \\
2 \text { - cônjuge } \\
3 \text { - cônjuge e } \\
\text { entrevistada } \\
4 \text { - outro parente } \\
5 \text { - outro parente e } \\
\text { entrevistada }\end{array}$ & \multirow[b]{2}{*}{$\begin{array}{l}2 \text { - sozinha } \\
1 \text { - entrevistada e } \\
\text { outras pessoas } \\
0 \text { - outras } \\
\text { pessoas }\end{array}$} & \multirow[b]{2}{*}{0} & \multirow[b]{2}{*}{12} \\
\hline & $\begin{array}{l}\text { Palavra final em: } \\
\text { compras de grande valor para a } \\
\text { casa? } \\
\text { cuidados com sua própria saúde? } \\
\text { compras para as necessidades } \\
\text { diárias? } \\
\text { visitas a família ou parentes? } \\
\text { comidas que devem ser } \\
\text { preparadas diariamente? }\end{array}$ & $\begin{array}{l}1 \text { - entrevistada } \\
2 \text { - cônjuge } \\
3 \text { - cônjuge e } \\
\text { entrevistada } \\
4 \text { - outro parente } \\
5 \text { - outro parente e } \\
\text { entrevistada } \\
96 \text { - outras pessoas }\end{array}$ & & & \\
\hline $\begin{array}{l}\text { Percepção } \\
\text { quanto ao } \\
\text { consenso } \\
\text { em uma } \\
\text { relação } \\
\text { sexual } \\
\text { (PCRS) }\end{array}$ & $\begin{array}{l}\text { Acha que a mulher pode recusar a } \\
\text { fazer sexo com o cônjuge quando: } \\
\text { sabe que ele tem uma DST? } \\
\text { sabe que ele faz sexo com outras } \\
\text { mulheres? } \\
\text { ela teve filho recentemente? } \\
\text { ela está cansada? } \\
\text { ela não quer? }\end{array}$ & $\begin{array}{l}1-\operatorname{sim} \\
2-\text { não } \\
98-\text { não sabe }\end{array}$ & $\begin{array}{l}1-\operatorname{sim} \\
0-\text { não ou não } \\
\text { sabe }\end{array}$ & 0 & 5 \\
\hline
\end{tabular}

Fonte: PNDS de 2006. Elaboração dos autores.

O Quadro 3 também expõe os valores mínimos e máximos dos índices, sendo a pontuação individual em cada índice calculada pelo somatório dos escores ponderados das suas perguntas componentes. Para que os índices variem entre zero e um, seguindo a literatura (HAQUE et al., 2011; VARGHESE, 2011; ISLAM et al., 2014), é realizada a transformação da equação (1).

Índice da dimensãa $=\frac{\text { pontuação obtida-pontuação máxima }}{\text { pontuação máxima-pontuaçãao obtida }}$

Para verificar a validade dos índices, aplica-se a técnica do alfa de Cronbach (1951) - equação (2) -, por meio da qual são averiguados os graus de consistência interna; ou seja, as capacidades de as variáveis utilizadas nos cálculos medirem os mesmos conceitos (constructos). 0 alfa de Cronbach varia entre zero e um e, quanto maior, melhor é a consistência interna, o que é desejado para um índice robusto. Há divergências quanto ao parâmetro ideal, mas, no geral, valores acima de 0,6 são aceitos e acima de 0,7 são tidos como adequados (VIEIRA, 2015).

$\alpha=\frac{k}{k-1}\left(1-\frac{\sum_{i=1}^{k} s_{i}^{2}}{S_{T}^{2}}\right)$ 
Onde: $k$ é o número de variáveis - quantidade de perguntas para cada um dos índices (Quadro 3) -; $\sum_{i=1}^{k} S_{i}^{2}$ corresponde ao somatório das variâncias da variável $i(i=1, \ldots, k)$; e $S_{T}^{2}$ é a variância das pontuações totais.

Dada a chance de subestimação do grau de confiabilidade, também é avaliado o alfa de Cronbach estandardizado. Este é calculado pela equação (2) com as variáveis com média zero e variância um (MAROCO; GARCIA-MARQUES, 2006). Os alfas de Cronbach tradicionais e estandardizados são mensurados para os dois índices de empoderamento, com as respectivas amostras totais de respondentes e, para verificar a robustez das evidências, com uma amostra balanceada composta por mulheres que responderam todas as perguntas para os dois índices.

Para o índice ED, a amostra total tem 7.824 mulheres; para o PCRS, 12.003 mulheres. $\mathrm{Na}$ amostra balanceada, há 7.809 mulheres. Na Tabela do Anexo constam as distribuições das mulheres das amostras, inclusive segundo os atributos selecionados.

Os alfas de Cronbach sugerem consistência interna nos índices. Os valores de todos estão próximos ou acima de 0,7. Para o índice ED, os alfas tradicional e estandardizado na amostra total são 0,76 e 0,75, respectivamente; na amostra balanceada, 0,73 e 0,71. Para o índice PCRS, os alfas tradicional e estandardizado na amostra total são 0,71 e 0,72, respectivamente; para a amostra balanceada, 0,67 e 0,68.

\section{Análises: caracterização do empoderamento feminino no Brasil}

Nesta seção, é caracterizado o empoderamento feminino no Brasil a partir dos dois índices aqui calculados. Para isso, são analisados médias, testes $t$ de diferenças de médias (BUSSAB; MORETTIN, 2013) e desvios padrão segundo: atributos locacionais (situação do domicílio e regiões); atributos pessoais (idade, anos de estudo, cor, estado conjugal, trabalho, renda e religião); e participação no $\mathrm{PBF}^{6}{ }^{6} \mathrm{~A}$ escolha destes atributos decorre de serem comumente defendidos como condicionantes do empoderamento. Ademais, além da consistência interna pelos alfas de Cronbach e das propriedades desejáveis em indicadores sociais (JANNUZZI, 2006), a observância de indícios similares a outros existentes sinalizará a validade dos índices.

Renda, educação e trabalho são apontados como alguns dos principais fomentadores do empoderamento feminino (LAVINAS; COBO; VEIGA, 2012; PHAN, 2015), enquanto os atributos "tradicionais", como idade, estado conjugal e religião, também podem conferir ou potencializar o "poder" das mulheres, principalmente em locais com fortes disparidades de gênero (JEJEEBHOY; SATHAR, 2001), como no Brasil. Os atributos locacionais buscam captar divergências geográficas no empoderamento, que, implicitamente, refletem diferenças históricas, culturais e legais (KHAN; AWAN, 2011).

\footnotetext{
${ }^{6}$ Os pesos de expansão da amostra disponibilizados pela PNDS são utilizados para obter resultados mais próximos da realidade (universo). Para os testes de diferenças de médias, é escolhida uma categoria base para cada atributo.
} 
O PBF é uma das maiores políticas de transferências condicionais de renda do mundo, tendo como objetivo o combate à fome e pobreza. Os benefícios são pagos prioritariamente às mulheres, sendo tal opção justificada pela premissa de que estas tendem a administrar melhor a renda familiar, zelando pelo bem-estar de toda a família (BARTHOLO et al., 2017). Mesmo não sendo um de seus objetivos explícitos, ao priorizar as mulheres, o PBF pode afetar o empoderamento das beneficiárias (SUÁREZ; LIBARDONI, 2007; DE BRAUW et al., 2014).

As médias, as significâncias de suas diferenças e os desvios padrão dos índices segundo atributos e amostras constam na Tabela 1. Observa-se que, nos dois índices, médias e desvios padrão variam pouco entre as amostras. Ademais, as médias do índice ED em todos os atributos são bem inferiores às do PCRS. A título de ilustração, seguindo Varghese (2011) e Islam et al. (2014), vale analisar segundo a categorização do Índice de Desenvolvimento Humano (IDH) da Organização das Nações Unidas (ONU). Para valores de IDH inferiores a 0,55, considera-se um nível baixo de desenvolvimento; entre 0,55 e 0,699, um nível intermediário; já acima de 0,7 , um nível alto. Portanto, na média, o empoderamento feminino brasileiro nas dimensões econômica e doméstica (índice ED) é intermediário e na psicológica (índice PCRS) é alto.

Observa-se pequena vantagem das mulheres urbanas nos dois índices de empoderamento, sendo as diferenças das médias rural-urbanas estatisticamente significantes. Segundo as grandes regiões brasileiras, não é clara a relação entre os níveis de desenvolvimento socioeconômico regional e de empoderamento. Por exemplo, Norte e Nordeste, que tendem a possuir os piores indicadores socioeconômicos (IBGE, 2019), não têm sempre as menores médias dos índices. ${ }^{7}$ Nessa linha, Souza (2012) e Bortoluzzo et al. (2016), em análises com índices sintéticos de igualdade de gênero, não apontam a renda como fator determinante de uma maior equidade, com estados do Norte-Nordeste com melhor desempenho do que Sul-Sudeste.

\footnotetext{
$\overline{7}$ Tomando o Norte como comparação, as médias das demais regiões são estatisticamente diferentes em quase todos os índices e amostras, excetuando-se o Centro-Oeste no índice PCRS.
} 
TABELA 1

Estatísticas descritivas dos índices de empoderamento feminino (médias e desvios padrão), por amostras, segundo atributos Brasil - 2006

\begin{tabular}{|c|c|c|c|c|}
\hline \multirow[b]{2}{*}{ Atributos } & \multicolumn{2}{|c|}{ ED } & \multicolumn{2}{|c|}{ PCRS } \\
\hline & Total & $\begin{array}{c}\text { Amostra } \\
\text { balanceada }\end{array}$ & Total & $\begin{array}{c}\text { Amostra } \\
\text { balanceada }\end{array}$ \\
\hline Brasil & $\begin{array}{c}0,6812 \\
(0,2339)\end{array}$ & $\begin{array}{c}0,6813 \\
(0,2339) \\
\end{array}$ & $\begin{array}{l}0,9261 \\
(0,1766) \\
\end{array}$ & $\begin{array}{r}0,9333 \\
(0,1647) \\
\end{array}$ \\
\hline \multicolumn{5}{|l|}{ Atributos locacionais } \\
\hline \multicolumn{5}{|l|}{ Região geográfica } \\
\hline Norte (1) & $\begin{array}{c}0,6545 \\
(0,2342)\end{array}$ & $\begin{array}{c}0,6547 \\
(0,2346)\end{array}$ & $\begin{array}{c}0,9493 \\
(0,1480)\end{array}$ & $\begin{array}{c}0,9520 \\
(0,1369)\end{array}$ \\
\hline Nordeste & $\begin{array}{c}0,6932^{\star \star \star} \\
(0,2418)\end{array}$ & $\begin{array}{c}0,6932^{\star \star \star} \\
(0,2418)\end{array}$ & $\begin{array}{c}0,9345^{\star \star} \\
(0,1645)\end{array}$ & $\begin{array}{l}0,9385^{\star} \\
(0,1613)\end{array}$ \\
\hline Sudeste & $\begin{array}{l}0,6771^{\star \star} \\
(0,2367)\end{array}$ & $\begin{array}{l}0,6771^{\star \star} \\
(0,2367)\end{array}$ & $\begin{array}{c}0,9133^{\star * \star} \\
(0,1914)\end{array}$ & $\begin{array}{c}0,9232^{\star \star \star} \\
(0,1753)\end{array}$ \\
\hline Sul & $\begin{array}{c}0,6815^{\star \star} \\
(0,2177)\end{array}$ & $\begin{array}{c}0,6816^{\star \star} \\
(0,2177)\end{array}$ & $\begin{array}{c}0,9316^{\star \star} \\
(0,1681)\end{array}$ & $\begin{array}{l}0,9380^{\star} \\
(0,1568)\end{array}$ \\
\hline Centro-Oeste & $\begin{array}{c}0,6928^{\star \star \star} \\
(0,2191)\end{array}$ & $\begin{array}{c}0,6931^{* * *} \\
(0,2193)\end{array}$ & $\begin{array}{c}0,9373 \\
(0,1626)\end{array}$ & $\begin{array}{c}0,9502 \\
(0,1439)\end{array}$ \\
\hline \multicolumn{5}{|l|}{ Situação dos domicílios } \\
\hline Urbanos (1) & $\begin{array}{c}0,6845 \\
(0,2335)\end{array}$ & $\begin{array}{c}0,6846 \\
(0,2335)\end{array}$ & $\begin{array}{c}0,9280 \\
(0,1734)\end{array}$ & $\begin{array}{c}0,9355 \\
(0,1613)\end{array}$ \\
\hline Rurais & $\begin{array}{c}0,6594^{* * *} \\
(0,2355)\end{array}$ & $\begin{array}{c}0,6596^{\star * \star} \\
(0,2356)\end{array}$ & $\begin{array}{c}0,9156^{\star \star \star} \\
(0,1926)\end{array}$ & $\begin{array}{c}0,9191^{\star * \star} \\
(0,1846)\end{array}$ \\
\hline \multicolumn{5}{|l|}{ Atributos pessoais } \\
\hline \multicolumn{5}{|l|}{ Faixas etárias } \\
\hline De 15 a 25 anos (1) & $\begin{array}{c}0,5531 \\
(0,2451)\end{array}$ & $\begin{array}{c}0,5531 \\
(0,2453)\end{array}$ & $\begin{array}{c}0,9175 \\
(0,1842)\end{array}$ & $\begin{array}{c}0,9207 \\
(0,1781)\end{array}$ \\
\hline De 26 a 35 anos & $\begin{array}{c}0,7036^{\star \star \star} \\
(0,2078)\end{array}$ & $\begin{array}{c}0,7036^{\star \star \star} \\
(0,2078)\end{array}$ & $\begin{array}{c}0,9407^{\star \star \star} \\
(0,1597)\end{array}$ & $\begin{array}{c}0,9435^{\star \star \star} \\
(0,1561)\end{array}$ \\
\hline De 36 a 49 anos & $\begin{array}{c}0,7557^{\star \star \star} \\
(0,2064)\end{array}$ & $\begin{array}{c}0,7557^{\star \star *} \\
(0,2064)\end{array}$ & $\begin{array}{c}0,9217 \\
(0,1820)\end{array}$ & $\begin{array}{c}0,9339^{\star \star \star} \\
(0,1609)\end{array}$ \\
\hline \multicolumn{5}{|l|}{ Anos de estudo } \\
\hline Até 5 anos (1) & $\begin{array}{c}0,7336 \\
(0,2202)\end{array}$ & $\begin{array}{c}0,7336 \\
(0,2202)\end{array}$ & $\begin{array}{c}0,9096 \\
(0,1992)\end{array}$ & $\begin{array}{c}0,9154 \\
(0,1904)\end{array}$ \\
\hline De 6 a 10 anos & $\begin{array}{c}0,6770^{* \star \star} \\
(0,2472)\end{array}$ & $\begin{array}{c}0,6771^{\star \star \star} \\
(0,2472)\end{array}$ & $\begin{array}{c}0,9197^{\star \star} \\
(0,1871)\end{array}$ & $\begin{array}{c}0,9300^{\star \star *} \\
(0,1678)\end{array}$ \\
\hline 11 anos ou mais & $\begin{array}{c}0,6580^{\star \star \star} \\
(0,2268)\end{array}$ & $\begin{array}{c}0,6581^{\star \star \star} \\
(0,2269)\end{array}$ & $\begin{array}{c}0,9423^{* \star \star} \\
(0,1479)\end{array}$ & $\begin{array}{c}0,9446^{\star \star *} \\
(0,1467)\end{array}$ \\
\hline \multicolumn{5}{|l|}{ Cor } \\
\hline Branca (1) & $\begin{array}{c}0,6848 \\
(0,2288)\end{array}$ & $\begin{array}{c}0,6849 \\
(0,2289)\end{array}$ & $\begin{array}{c}0,9276 \\
(0,1753)\end{array}$ & $\begin{array}{c}0,9408 \\
(0,1528)\end{array}$ \\
\hline Preta & $\begin{array}{l}0,7050^{\star \star} \\
(0,2394)\end{array}$ & $\begin{array}{l}0,7051^{\star *} \\
(0,2394)\end{array}$ & $\begin{array}{l}0,9151^{\star \star} \\
(0,2115)\end{array}$ & $\begin{array}{c}0,9335 \\
(0,1734)\end{array}$ \\
\hline Parda & $\begin{array}{c}0,6770 \\
(0,2356)\end{array}$ & $\begin{array}{c}0,6770 \\
(0,2356)\end{array}$ & $\begin{array}{c}0,9263 \\
(0,1720)\end{array}$ & $\begin{array}{c}0,9256^{\star \star *} \\
(0,1748)\end{array}$ \\
\hline Amarela & $\begin{array}{c}0,6370^{\star * *} \\
(0,2309)\end{array}$ & $\begin{array}{c}0,6377^{\star \star \star} \\
(0,2312)\end{array}$ & $\begin{array}{c}0,9295 \\
(0,1462)\end{array}$ & $\begin{array}{c}0,9371 \\
(0,1518)\end{array}$ \\
\hline Indígena & $\begin{array}{l}0,6425^{\star \star} \\
(0,2590)\end{array}$ & $\begin{array}{c}0,6425^{\star \star} \\
(0,2590)\end{array}$ & $\begin{array}{c}0,9408 \\
(0,1498)\end{array}$ & $\begin{array}{c}0,9465 \\
(0,1218)\end{array}$ \\
\hline \multicolumn{5}{|l|}{ Estado conjugal } \\
\hline Com cônjuge (1) & $\begin{array}{c}0,7043 \\
(0,1885)\end{array}$ & $\begin{array}{c}0,7044 \\
(0,1885)\end{array}$ & $\begin{array}{c}0,9251 \\
(0,1743)\end{array}$ & $\begin{array}{c}0,9330 \\
(0,1611)\end{array}$ \\
\hline Sem cônjuge & $\begin{array}{c}0,6335^{\star \star \star} \\
(0,3016)\end{array}$ & $\begin{array}{c}0,6335^{\star \star \star} \\
(0,3017)\end{array}$ & $\begin{array}{c}0,9283 \\
(0,1816)\end{array}$ & $\begin{array}{c}0,9341 \\
(0,1719)\end{array}$ \\
\hline
\end{tabular}


(Continuação)

\begin{tabular}{|c|c|c|c|c|}
\hline \multirow{2}{*}{ Atributos } & \multicolumn{2}{|c|}{ ED } & \multicolumn{2}{|c|}{ PCRS } \\
\hline & Total & $\begin{array}{c}\text { Amostra } \\
\text { balanceada }\end{array}$ & Total & $\begin{array}{c}\text { Amostra } \\
\text { balanceada }\end{array}$ \\
\hline \multicolumn{5}{|l|}{ Trabalho } \\
\hline Com trabalho (1) & $\begin{array}{c}0,6904 \\
(0,2306)\end{array}$ & $\begin{array}{c}0,6905 \\
(0,2306)\end{array}$ & $\begin{array}{c}0,9333 \\
(0,1651)\end{array}$ & $\begin{array}{c}0,9368 \\
(0,1597)\end{array}$ \\
\hline Sem trabalho & $\begin{array}{c}0,6298^{\star \star \star} \\
(0,2454)\end{array}$ & $\begin{array}{c}0,6297^{\star \star \star} \\
(0,2455)\end{array}$ & $\begin{array}{c}0,9155^{\star \star *} \\
(0,1915)\end{array}$ & $\begin{array}{c}0,9142^{\star \star \star} \\
(0,1891)\end{array}$ \\
\hline \multicolumn{5}{|l|}{$\begin{array}{l}\text { Faixas de renda domiciliar } \\
\text { mensal per capita } \\
\text { (em salários mínimos de 2006) }\end{array}$} \\
\hline Até 1/2 SM (1) & $\begin{array}{c}0,7020 \\
(0,2731)\end{array}$ & $\begin{array}{c}0,7019 \\
(0,2731)\end{array}$ & $\begin{array}{c}0,9239 \\
(0,1893)\end{array}$ & $\begin{array}{c}0,9197 \\
(0,1951)\end{array}$ \\
\hline Mais de $1 / 2$ a $1 \mathrm{SM}$ & $\begin{array}{c}0,7142 \\
(0,2437)\end{array}$ & $\begin{array}{c}0,7143 \\
(0,2438)\end{array}$ & $\begin{array}{l}0,9071^{\star *} \\
(0,2120)\end{array}$ & $\begin{array}{l}0,9038^{\star} \\
(0,2166)\end{array}$ \\
\hline Mais de 1 a 2 SM & $\begin{array}{c}0,6942 \\
(0,2467)\end{array}$ & $\begin{array}{c}0,6945 \\
(0,2468)\end{array}$ & $\begin{array}{c}0,9154 \\
(0,1824)\end{array}$ & $\begin{array}{c}0,9189 \\
(0,1793)\end{array}$ \\
\hline Mais de 2 a 3 SM & $\begin{array}{c}0,6649^{\star * \star} \\
(0,2321)\end{array}$ & $\begin{array}{c}0,6649^{* * *} \\
(0,2321)\end{array}$ & $\begin{array}{l}0,9364^{*} \\
(0,1577)\end{array}$ & $\begin{array}{c}0,9401^{\star \star} \\
(0,1466)\end{array}$ \\
\hline Mais de 3 a 5 SM & $\begin{array}{c}0,6692^{\star * \star} \\
(0,2154)\end{array}$ & $\begin{array}{c}0,6693^{* * *} \\
(0,2154)\end{array}$ & $\begin{array}{c}0,9307 \\
(0,1574)\end{array}$ & $\begin{array}{c}0,9419^{\star \star \star} \\
(0,1385)\end{array}$ \\
\hline Mais de 5 a 10 SM & $\begin{array}{c}0,6634^{* * *} \\
(0,2219)\end{array}$ & $\begin{array}{c}0,6635^{\star \star \star} \\
(0,2220)\end{array}$ & $\begin{array}{c}0,9404^{\star \star} \\
(0,1687)\end{array}$ & $\begin{array}{c}0,9569^{\star \star *} \\
(0,1289)\end{array}$ \\
\hline Mais de 10 a 20 SM & $\begin{array}{c}0,6628^{\star \star \star} \\
(0,1945)\end{array}$ & $\begin{array}{c}0,6628^{\star \star \star} \\
(0,1945)\end{array}$ & $\begin{array}{l}0,9402^{*} \\
(0,1410)\end{array}$ & $\begin{array}{c}0,9510^{\star \star \star} \\
(0,1347)\end{array}$ \\
\hline Mais de 20 SM & $\begin{array}{c}0,6873 \\
(0,1549)\end{array}$ & $\begin{array}{c}0,6873 \\
(0,1549)\end{array}$ & $\begin{array}{c}0,9733^{\star * *} \\
(0,0957)\end{array}$ & $\begin{array}{c}0,9823^{* * *} \\
(0,0792)\end{array}$ \\
\hline \multicolumn{5}{|l|}{ Religião } \\
\hline Católica (1) & $\begin{array}{c}0,6839 \\
(0,2318)\end{array}$ & $\begin{array}{c}0,6840 \\
(0,2318)\end{array}$ & $\begin{array}{c}0,9350 \\
(0,1641)\end{array}$ & $\begin{array}{c}0,9395 \\
(0,1586)\end{array}$ \\
\hline Evangélica & $\begin{array}{c}0,6763 \\
(0,2318)\end{array}$ & $\begin{array}{c}0,6762 \\
(0,2319)\end{array}$ & $\begin{array}{c}0,9031^{\star * *} \\
(0,1981)\end{array}$ & $\begin{array}{c}0,9128^{\star \star \star} \\
(0,1786)\end{array}$ \\
\hline Outras & $\begin{array}{c}0,6809 \\
(0,2385)\end{array}$ & $\begin{array}{c}0,6809 \\
(0,2385)\end{array}$ & $\begin{array}{l}0,9425 \\
(0,1700)\end{array}$ & $\begin{array}{l}0,9483 \\
(0,1575)\end{array}$ \\
\hline Nenhuma & $\begin{array}{c}0,6764 \\
(0,2533)\end{array}$ & $\begin{array}{c}0,6765 \\
(0,2535)\end{array}$ & $\begin{array}{c}0,9178^{\star \star \star} \\
(0,1947)\end{array}$ & $\begin{array}{c}0,9400 \\
(0,1639)\end{array}$ \\
\hline \multicolumn{5}{|l|}{ Programa Bolsa Família (PBF) } \\
\hline Beneficiárias (1) & $\begin{array}{c}0,7074 \\
(0,2381)\end{array}$ & $\begin{array}{c}0,7074 \\
(0,2381)\end{array}$ & $\begin{array}{c}0,9272 \\
(0,1677)\end{array}$ & $\begin{array}{c}0,9354 \\
(0,1561)\end{array}$ \\
\hline Não beneficiárias & $\begin{array}{c}0,6755^{\star * \star} \\
(0,2326)\end{array}$ & $\begin{array}{c}0,6756^{\star * \star} \\
(0,2326)\end{array}$ & $\begin{array}{c}0,9258 \\
(0,1786)\end{array}$ & $\begin{array}{c}0,9329 \\
(0,1665) \\
\end{array}$ \\
\hline
\end{tabular}

Fonte: PNDS 2006. Elaboração dos autores.

(1) Categoria base.

Nota: Desvio padrão entre parênteses. Diferença da média em relação à média da categoria base é estatisticamente significante a: *** $1 \%$; $* * 5 \%$; $10 \%$.

Iniciando as análises dos atributos pessoais, nota-se que, quanto maior a idade, maior é a média do índice ED - médias estatisticamente distintas -, ou seja, maior tende a ser a capacidade de a mulher decidir sobre questões econômicas e domiciliares. As mais jovens têm média do índice ED inferior àquelas com maiores idades, estando as da maior faixa etária em melhor situação, na média, e com menor discrepância (desvio-padrão) entre suas integrantes. No índice PCRS, não há padrão claro de variação pela idade - a média altera pouco entre as faixas e as mulheres do grupo etário intermediário têm melhor situação (média e desvio padrão). 
0 aumento dos anos de estudo não tende a melhorar o empoderamento feminino pelo índice ED; ao contrário, há redução da média do índice à medida que aumenta a faixa de escolaridade - as diferenças das médias entre as faixas são significantes. Tal resultado contradiz uma possível expectativa de relação positiva entre empoderamento e escolaridade. Por outro lado, no índice PCRS, tal relação é sinalizada: mulheres com mais escolaridade tendem a ter melhores situações (maiores médias e menores desvios padrão), sendo significante a diferença das médias da segunda e terceira faixas de escolaridade em relação à primeira. Assim, sugere-se uma melhora conforme a escolaridade da percepção das mulheres sobre o controle de seus desejos em relações sexuais.

As mulheres autodeclaradas amarelas têm a menor média do índice de empoderamento ED e as pretas a maior, enquanto a segunda maior média neste índice é a das mulheres brancas, que também possuem a menor discrepância (desvio padrão) entre suas integrantes. As médias do índice ED entre amarelas e pretas relativamente às brancas são estatisticamente diferentes.

Em contrapartida, mesmo que bem próximas às demais, as mulheres pretas têm a menor média do índice PCRS e maior discrepância (desvio padrão) entre as integrantes. Já as indígenas apresentam a maior média do índice PCRS. Contudo, não há evidências robustas de que as médias do índice PCRS são estatisticamente diferentes entre as cores. Nesse atributo, portanto, não há um padrão similar de diferenças de médias de empoderamento nos dois índices.

As mulheres com cônjuge apresentam média do índice ED superior à das mulheres sem cônjuge (médias estatisticamente diferentes) e, também, menor discrepância (desvio padrão) entre suas integrantes. ${ }^{8}$ Estas evidências sugerem maior subordinação das mulheres a outros parentes - talvez, principalmente aos pais - do que aos cônjuges em questões econômicas e domésticas. No índice PCRS, as diferenças das médias são estatisticamente insignificantes.

Destaca-se, ainda, que as mulheres com trabalho remunerado possuem, nos dois índices, médias superiores e estatisticamente diferentes às daquelas "sem trabalho" e menores discrepâncias (desvios padrão) entre suas integrantes. A maior diferença de médias a favor das mulheres com trabalho é no índice ED. Ressalta-se que, ao diferenciar o empoderamento das mulheres com e sem trabalho, é observado, implicitamente, o impacto de ter uma renda própria.

Nessa linha, é interessante avaliar a tendência do empoderamento em função da renda per capita mensal do domicílio. Pelo índice PCRS, sugere-se uma relação média positiva, chegando a mais de 0,97 para as mulheres em domicílios da última faixa de renda. Porém, relação similar não é clara no índice ED, pois na segunda e última faixas de renda há reversão da tendência de elevação do empoderamento conforme aumenta a renda domiciliar. Nos

\footnotetext{
${ }^{8}$ As mulheres "com cônjuge" são aquelas que se autodeclararam formalmente casadas ou em união estável; já as "sem cônjuge” correspondem às solteiras, viúvas, separadas, desquitadas ou divorciadas.
} 
dois índices, as médias são estatisticamente diferentes relativamente ao menor extrato de renda a partir da quarta faixa.

Cabe apontar, ainda, o empoderamento segundo a religiosidade. Respeitando a tipologia da PNDS, são considerados quatro grupos: católica, evangélica, outras e nenhuma. ${ }^{9}$ Mulheres sem religião ou evangélicas têm as menores médias nos dois índices, mas não há um padrão claro em relação às discrepâncias (desvios padrão). Comparativamente às católicas, somente a média das evangélicas no índice PCRS é estatisticamente diferente.

Finalmente, as evidências da Tabela 1 sugerem que o PBF gerou repercussões positivas no empoderamento das beneficiárias, em especial nas dimensões econômica e doméstica. No índice ED, as médias das beneficiárias são superiores e estatisticamente diferentes às das não beneficiárias; porém, também com maior discrepância (desvio padrão). No índice PCRS, as médias também são maiores para as beneficiárias, mas as diferenças não são estatisticamente significantes.

Comentadas as evidências encontradas, vale fazer apontamentos adicionais à luz da literatura. Primeiramente, o fato de um índice poder ser afetado por um atributo da mulher e outro não ou as relações serem distintas ratifica a tese da literatura de que o empoderamento feminino é um fenômeno multidimensional. Assim, nada garante que um atributo afete de forma similar diferentes dimensões do empoderamento (MALHOTRA; MATHER, 1997; MASON; SMITH, 2003). Aqui, tal fato é sinalizado, por exemplo, pelos atributos idade, anos de estudo e renda domiciliar, para os quais são sugeridas relações distintas nos dois índices calculados.

Ressalta-se, ainda, que o fato de os anos de estudo e a renda domiciliar não terem uma relação positiva clara nas dimensões ED, ao menos na média, indica que a ausência (ou a baixa) de autonomia em escolhas econômicas e domésticas pode não ser restrita a mulheres em situação de vulnerabilidade socioeconômica. Para Mageste et al. (2008), se o status econômico fosse suficiente, mulheres mais escolarizadas e com maior remuneração não seriam subordinadas às vontades dos maridos. As evidências existentes, inclusive com aplicações para índices sintéticos de empoderamento feminino, não estabelecem um consenso e, ao diferirem entre localidades, parecem ser sensíveis a outros atributos.

Enquanto alguns trabalhos demonstraram que maiores escolaridades elevam o empoderamento (KHAN; AWAN, 2011; ASSAAD et al., 2014; PHAN, 2015), outros apresentaram evidências na linha do presente estudo, sugerindo que a educação pode ser insuficiente ou inefetiva, principalmente em contextos sociais fortemente pautados em normas e costumes patriarcais. Jejeebhoy e Sathar (2001), por exemplo, observaram que a autonomia das mulheres indianas e paquistanesas é limitada e seus determinantes divergem entre regiões. Naquelas com maior desigualdade de gênero, os principais são aqueles tidos como "tradicionais", como idade, duração do casamento e número de filhos do sexo masculino vivos; já nas regiões com maior igualdade de gênero, a educação exerce papel fundamental.

\footnotetext{
${ }^{9}$ Para a religião evangélica, são agregadas as tradicionais e as pentecostais. Já como “outras”, as religiões espírita, afrobrasileira e demais não detalhadas na PNDS.
} 
Os resultados de Mason e Smith (2003), ao analisarem o empoderamento doméstico de mulheres casadas de países asiáticos, contribuem para o argumento de que as normas e valores da sociedade, como religião e etnia, são determinantes mais fundamentais das relações de gênero do que atributos individuais, como educação e emprego. Já Al Riyami et al. (2004), com avaliações das relações entre empoderamento e contracepção em Omã, mostraram que a educação é um condicionante importante do uso e demanda de contraceptivos, mas não o empoderamento - mais de 50\% das mulheres com formação universitária afirmaram que era o marido que decidia usar ou não algum método de planejamento familiar, contra $38,5 \%$ das mulheres não alfabetizadas.

Em conjunto com o possível efeito positivo da idade, essas evidências podem indicar, ao menos em algumas localidades, o que Jejeebhoy e Sathar (2001) advogam como uma maior relevância relativa de aspectos tidos como "tradicionais" para fomentar a maior autonomia das mulheres em decisões de cunhos econômico e doméstico. Logo, ações focadas exclusivamente em educação e geração de renda podem não alcançar o nível de empoderamento desejado devido à força de determinantes culturais e sociais.

Ademais, as evidências ressaltam a importância do trabalho. Nas dimensões intrínsecas aos índices, o fato de a mulher estar engajada em alguma atividade remunerada impacta positivamente o seu empoderamento - aumento dos dois índices -, corroborando discussões e resultados de outras pesquisas sobre as vantagens de possuir um trabalho para o processo de emancipação feminina (LAVINAS; COBO; VEIGA, 2012; PHAN, 2015).

Outro destaque refere-se às diferenças das médias do empoderamento entre áreas urbanas e rurais, tal como em outros trabalhos (KHAN; AWAN, 2011; DE BRAUW et al., 2014), e regiões, mesmo com indícios inesperados. Tais evidências sugerem a importância de fatores históricos e culturais - e não apenas socioeconômicos -, distintos entre os locais, na manutenção de aspectos que sedimentam as disparidades de gênero (KHAN; AWAN, 2011).

As evidências deste estudo somam-se a outras para sugerir efeitos positivos do PBF para as mulheres. Segundo alguns trabalhos, elas interpretam o recebimento dos benefícios como favorável. Outros sinalizam efeitos benéficos no mercado de trabalho, nas relações domésticas - inclusive, reduzindo a violência - e com agentes externos e em termos de autonomia e cidadania (SUÁREZ; LIBARDONI, 2007; AHLERT, 2013; REGO; PINZANI, 2013; DE BRAUW et al., 2014; PASSOS; WALTENBERG, 2016; BARTHOLO et al., 2017).

Portanto, é possível cogitar, nos termos de Berth (2019), que o PBF pode ter ajudado a desenvolver um ambiente favorável à disseminação e à proliferação de práticas empoderadas por parte das mulheres. Bartholo et al. (2017) ressalvam que o programa, por mais que possa não romper algumas relações culturais e históricas deletérias de gênero, pode ter contribuído para alterar aspectos ligados à cidadania e ampliado liberdades importantes para as mulheres. 


\section{Considerações finais}

Fundamentando-se nas literaturas teórica e empírica e utilizando a PNDS de 2006, neste estudo foram propostos e calculados dois índices de empoderamento feminino para o Brasil. 0 índice ED sintetiza a capacidade das mulheres de afetarem decisões individuais e familiares e, pela tipologia aqui estabelecida, sinaliza as dimensões econômica e doméstica do empoderamento a nível individual. Já o índice PCRS capta a percepção da mulher sobre o direito de negar relações sexuais em diferentes cenários e, na referida tipologia, é enquadrado na dimensão psicológica, também a nível individual.

Quanto maior a pontuação do índice, que varia de 0 a 1, maior é o empoderamento da mulher na dimensão em questão. Como os índices captam diferentes dimensões de um mesmo fenômeno, que, por sua vez, apresentam inúmeros condicionantes sociais, econômicos, culturais e históricos, é plausível que os resultados de um grupo de mulheres sejam heterogêneos conforme os índices - o que foi constatado nas análises.

Os dois índices foram calculados para todas as mulheres da amostra da PNDS e, a partir de médias, testes de diferenças de médias e desvios padrão, foi caracterizado o empoderamento feminino no Brasil segundo atributos locacionais e pessoais tradicionalmente defendidos como condicionantes do processo. Ademais, com os índices calculados, foram apresentados indícios adicionais para o debate sobre efeitos do PBF no empoderamento.

As evidências sinalizam, como preconizado na literatura, o caráter multidimensional do empoderamento feminino em termos de seus condicionantes - no sentido de alguns atributos influenciarem de forma distinta as dimensões aqui consideradas - e reforçam a importância de a mulher ter um emprego para o empoderamento. Assim como em outros trabalhos, algumas evidências sugerem também impactos positivos do PBF no empoderamento feminino, o que pode ser atribuído, ao menos em parte, ao pagamento prioritário às mulheres.

Vale ressalvar que o estudo tem limitações, sendo a principal o uso de dados de 2006. As evidências aqui apresentadas ainda são relevantes para reflexões sobre o empoderamento das brasileiras, já que não é possível desconsiderar que mudanças de paradigmas sociais demandam tempo. Isso não muda a necessidade de dados mais recentes, periódicos e representativos que permitam análises contínuas das vivências das mulheres no país. Em tempo, este estudo apresenta evidências que podem fundamentar análises futuras de evoluções dos aspectos observados com dados mais recentes, como os da nova PNDS, prevista para os próximos anos.

Outra limitação metodológica é a utilização de médias e desvios padrão para sinalizar as relações, o que prejudica a atribuição de causalidade. 0 principal intuito era calcular, de forma relativamente pioneira, dois índices sintéticos de empoderamento feminino no Brasil e, por meio deles e dos atributos selecionados, caracterizar tal processo no país. Porém, considerando as significâncias estatísticas dos testes de diferenças de médias e as semelhanças com resultados de outros trabalhos, as evidências não podem ser 
menosprezadas e conseguem contribuir para subsidiar ações de diferentes setores para o fomento do empoderamento feminino.

Por exemplo, as evidências sugerem que a inserção da mulher no mercado de trabalho é importante para o empoderamento, mas outros condicionantes pessoais e locacionais - por refletirem, em algum grau, fatores históricos e culturais - também são relevantes. Assim, ações voltadas apenas para a renda e educação podem não ser suficientes para transformar o papel da mulher em uma sociedade com fortes bases patriarcais como a brasileira, sendo necessário pensar em medidas que lidem com os fatores tradicionais que subjugam a mulher.

\section{Referências}

AL RIYAMI, A.; AFIFI, M.; MABRY, R. Women's autonomy, education and employment in Oman and their influence on contraceptive use. Reproductive Health Matters, v. 12, n. 23, 2004.

AHLERT, M. A "precisão" e o "luxo": usos do benefício do Programa Bolsa Família entre as quebradeiras de coco de Codó (MA). Política e Trabalhos - Revista de Ciências Sociais, n. 38, p. 69-86, 2013.

ALSOP, R.; DUDWICK, N.; BERTELSEN, M.; JONES, V. Empowerment in practice: analysis and implementation. Washington: World Bank, 2007.

ARESTOFF, F.; DJEMAI, E. Women's empowerment across the life cycle and generations: evidence from Sub-Saharan Africa. World Development, v. 87, p. 70-87, 2016.

ASSAAD, R.; NAZIER, H.; RAMADAN, R. Individual and households determinants of women empowerment: application to the case of Egypt. Giza, Egypt: Economic Research Forum, 2014 (Working Paper, n. 867).

BARTHOLO, L.; PASSOS, L.; FONTOURA, N. Bolsa Família, autonomia feminina e equidade de gênero: o que indicam as pesquisas nacionais? Rio de Janeiro: Ipea, 2017. (Texto para Discussão, n. 2331).

BASTOS, A.; COSTA, B.; ANDRADE, D.; DAHAS, D.; SOUTO, G. Insurreição de gênero nos espaços de poder: a representatividade feminina na política brasileira à luz da reforma eleitoral. Belo Horizonte: Motres, 2018.

BATLIWALA, S. El significado del empoderamiento de las mujeres: nuevos conceptos desde la acción. In: LEÓN, M. (comp.). Poder y empoderamiento de las mujeres. Bogotá: T/M Editores, 1997. p. 187-211.

BERTH, J. Empoderamento. São Paulo: Pólen, 2019. (Coleção Feminismos Plurais).

BORTOLUZZO, A.; MATAVELLI, I.; MADALOZZO, R. Determinantes da distribuição da (des)igualdade de gênero entre os estados brasileiros. Estudos Econômicos, v. 46, n. 1, p. 161-188, 2016.

BUSSAB, W.; MORETTIN, P. Estatística básica. 8. ed. São Paulo: Saraiva, 2013.

CRONBACH, L. Coefficient alpha and the internal structure of tests. Psychometrika, v. 16, p. 297-334, 1951.

DE BRAUW, A.; GILLIGAN, D.; HODDINOTT, J.; ROY, S. The impact of Bolsa Família on women's decision-making power. World Development, v. 59, p. 487-504, 2014. 
DELPHY, C. Patriarcado (Teorias do). In: HIRATA, H.; LABORIE, F.; DOARÉ, H.; SENOTIER, D. (org.). Dicionário crítico do feminismo. São Paulo: Unesp, 2009.

DO, M.; KURIMOTO, N. Women's empowerment and choice of contraceptive methods in selected African countries. International Perspectives on Sexual and Reproductive Health, v. 38, n. 1, p. 23-33, 2012.

EWERLING, F.; LYNCH, J.; VICTORA, C.; VAN EERDEWIJK, A.; TYSZLER, M.; BARROS, A. The SWPER index for women's empowerment in Africa: development and validation of an index based on survey data. The Lancet, Global Health, v. 5, n. 9, p. E916-E923, 2017.

GUPTA, K.; YESUDIAN, P. Evidence of women's empowerment in India: a study of socio-spatial disparities. GeoJournal, v. 65, p. 365-380, 2006.

HAQUE, M.; ISLAM, T.; TAREQUE, I.; MOSTOFA, G. Women empowerment or autonomy: a comparative view in Bangladesh context. Bangladesh e-Journal of Sociology, v. 8, n. 2, p. 17-30, 2011.

IBGE - Instituto Brasileiro de Geografia e Estatística. Síntese de indicadores sociais: uma análise das condições de vida da população brasileira. Estudos \& Pesquisas, n. 40, 2019.

ISLAM, T.; TAREQUE, I.; TIEDT, A.; HOQUE, N. The intergenerational transmission of intimate partner violence in Bangladesh. Global Health Action, v. 7, n. 1, 2014.

JANNUZZI, P. Indicadores sociais no Brasil: conceitos, fontes de dados e aplicações. 3. ed. Campinas: Alínea, 2006.

JEJEEBHOY, S.; SATHAR, Z. Women's autonomy in India and Pakistan: the influence of religion and region. Population and Development Review, v. 27, n. 4, p. 687-712, 2001.

KHAN, S.; AWAN, R. Contextual assessment of women empowerment and its determinants: evidence from Pakistan. Munich Personal RePEc Archive, 2011 (MPRA Paper, n. 30820).

LAVINAS, L.; COBO, B.; VEIGA, A. Bolsa Família: impacto das transferências de renda sobre a autonomia das mulheres pobres e as relações de gênero. Revista Latinoamericana de Población, v. 6, n. 10, 2012.

LEÓN, M. El empoderamiento de las mujeres: encuentro del primer y tercer mundos em los estúdios de género. La Ventana, n. 13, p. 94-106, 2001.

LISBOA, T. O empoderamento como estratégia de inclusão das mulheres nas políticas sociais. In: SEMINÁRIO INTERNACIONAL FAZENDO GÊNERO 8 - CORPO, VIOLÊNCIA E PODER. Anais [...]. Florianópolis: UFSC, 2008.

MAGESTE, G.; MELO, M.; CKAGNAZAROFF, I. Empoderamento de mulheres: uma proposta de análise para as organizações. In: V ENCONTRO DE ESTUDOS ORGANIZACIONAIS DA ANPAD. Anais [...]. Belo Horizonte: Anpad, 2008.

MALHOTRA, A.; MATHER, M. Do schooling and work empower women in developing countries? Gender and domestic decisions in Sri Lanka. Sociological Forum, v. 12, n. 4, p. 599-630, 1997.

MAROCO, J.; GARCIA-MARQUES, T. Qual a fiabilidade do alfa de Cronbach? Questões antigas e soluções modernas? Laboratório de Psicologia, v. 4, n. 1, p. 65-90, 2006.

MASON, K.; SMITH, H. Women's empowerment and social context: results from five Asian countries. Washington, DC: Gender and Development Group, World Bank, 2003.

PASSOS, L.; WALTENBERG, F. Bolsa Família e assimetrias de gênero: reforço ou mitigação? Revista Brasileira de Estudos de População, v. 33, n. 3, p. 517-539, 2016. 
PHAN, L. Measuring women's empowerment at household level using DHS Data of Four Southeast Asian countries. Social Indicators Research, n. 126, p. 359-378, 2015.

PNDS - Pesquisa Nacional de Demografia e Saúde da Criança e da Mulher. PNDS 2006: Relatório final. Brasília: Ministério da Saúde, 2008.

RAJ, A. Gender empowerment index: a choice of progress or perfection. The Lancet, Global Health, v. 5, n. 9, p. E849-E850, 2017.

REGO, W.; PINZANI, A. Liberdade, dinheiro e autonomia: o caso da Bolsa Família. Revista de Ciências Sociais, v. 38, p. 21-42, 2013.

ROWLANDS, J. Empowerment examined. Development in Practice, v. 5, n. 2, p. 101-107, 1995.

SOARES, C. O desenvolvimento social e o empoderamento econômico das mulheres no Brasil: uma análise a partir de índices sintéticos. Cadernos Adenauer, v. VIV, n. 3, p. 51-70, 2013.

SOUZA, L. A mensuração da desigualdade de gênero: um índice para os estados brasileiros. Monografia (Graduação em Ciências Econômicas) - Universidade de Brasília (UnB), Brasília, 2012.

STROMQUIST, N. La búsqueda del empoderamiento: en qué puede contribuir el campo de la educación. In: LEÓN, M. (org.). Poder y empoderamiento de las mujeres. Bogotá: TM Editores, 1997.

SUÁREZ, M.; LIBARDONI, M. O impacto do Programa Bolsa Família: mudanças e continuidades na condição social das mulheres. In: VAITSMAN, J.; PAES-SOUSA, R. Avaliação de políticas e programas do MDS - resultados: Bolsa Família e Assistência Social. Brasília: MDS, 2007. v. 2.

VARGHESE, T. Women empowerment in Oman: a study based on women empowerment index. Far East Journal of Psychology and Business, v. 2, n. 2, p. 37-53, 2011.

VIEIRA, S. Alfa de Cronbach. 2015. Disponível em: http://soniavieira.blogspot.com/. Acesso em: maio 2019.

\section{Sobre os autores}

Maria Carolina do Amaral Couto é doutoranda em Economia pelo Programa de Pós-Graduação em Economia da Universidade Federal de Uberlândia (UFU), com apoio financeiro da Coordenação de Aperfeiçoamento de Pessoal de Nível Superior (Capes), e mestre em Economia pela mesma universidade, tendo recebido apoio financeiro da Fundação de Amparo à Pesquisa do Estado de Minas Gerais (Fapemig).

Carlos César Santejo Saiani é doutor em Economia pela Escola de Economia de São Paulo da Fundação Getúlio Vargas (EESP/FGV) e mestre em Economia pela Faculdade de Economia, Administração e Contabilidade de Ribeirão Preto da Universidade de São Paulo (FEARP/USP). Professor adjunto do Instituto de Economia e Relações Internacionais da Universidade Federal de Uberlândia (IERI/UFU).

\section{Endereço para correspondência}

Maria Carolina do Amaral Couto

Rua Irmã Dulce, n. 55, apto. 102, Santa Mônica

38408-734 - Uberlândia-MG, Brasil

Carlos César Santejo Saiani

Rua Péricles Vieira da Mota, n. 1515, apto. 503, Santa Mônica

38408-220 - Uberlândia-MG, Brasil 


\begin{abstract}
Dimensions of Women's Empowerment in Brazil: Indexes and Characterization by Locational and Individual Attributes and Participation in the Bolsa Família Program
\end{abstract}

Overcoming gender inequalities in a society with strong patriarchal bases, such as the Brazilian one, has women's empowerment as one of its central elements. Given its importance for the transformation of the social role of women, it is essential to discuss promotion, strengthening and measurement actions. To support this debate, the construction of synthetic indexes of empowerment has been gaining prominence in the literature, which is still underexplored in Brazil. This study contributes to fill this gap. Using data from the 2006 National Survey of Demography and Health of Children and Women (PNDS), the objectives were: to propose and calculate two synthetic indexes of women's empowerment, which reflect economic, domestic and psychological dimensions; and with these indexes, to characterize the situation in Brazil according to locational and individuals attributes and participation in the Bolsa Família Program (PBF). The evidence suggests empowerment as a multidimensional character, the importance of work and other personal and locational attributes and possible effects of the PBF on the economic and domestic dimensions of its beneficiaries's empowerment.

Keywords: Women’s empowerment. Indexes. Bolsa Família Program.

\title{
Resumen
}

Dimensiones del empoderamiento femenino en Brasil: índices y caracterización por atributos locales e individuales y participación en el Programa Bolsa Família

La superación de las desigualdades de género en una sociedad con fuertes bases patriarcales, como la brasileña, tiene como uno de sus elementos centrales el empoderamiento femenino. Dada su importancia para la transformación del papel social de la mujer, es fundamental discutir acciones de promoción, fortalecimiento y medición. Para sustentar este debate, la construcción de índices sintéticos de empoderamiento ha ido ganando protagonismo en la literatura, aún poco explorada en Brasil. Este estudio contribuye a llenar el vacío. Utilizando información de la Encuesta Nacional de Demografía y Salud de la Infancia y la Mujer (PNDS) de 2006, los objetivos del presente estudio fueron: proponer y calcular dos índices sintéticos de empoderamiento femenino que reflejen dimensiones económicas, domésticas y psicológicas; y con estos índices, caracterizar la situación en Brasil de acuerdo con los atributos de ubicación y individual y participación en el Programa Bolsa Família (PBF). La evidencia sugiere un carácter multidimensional del empoderamiento, la importancia del trabajo y otros atributos individuales y de ubicación y los posibles efectos del PBF en las dimensiones económicas y domésticas del empoderamiento de sus beneficiarias.

Palabras clave: Empoderamiento femenino. Índices. Programa Bolsa Família. 


\section{Anexo}

Distribuições das mulheres da PNDS, por amostra e índices de empoderamento feminino, segundo atributos

Brasil - 2006

\begin{tabular}{|c|c|c|c|}
\hline \multirow{3}{*}{ Atributos } & & & \multirow{2}{*}{$\begin{array}{c}\text { Em porcentagen } \\
\begin{array}{c}\text { Amostra } \\
\text { balanceada }\end{array}\end{array}$} \\
\hline & \multicolumn{2}{|c|}{ Amostra total } & \\
\hline & ED & PCRS & ED e PCRS \\
\hline \multicolumn{4}{|l|}{ Região geográfica } \\
\hline Norte & 7,34 & 8,17 & 7,32 \\
\hline Nordeste & 24,40 & 25,46 & 24,42 \\
\hline Sudeste & 45,25 & 44,50 & 45,28 \\
\hline Sul & 15,72 & 14,52 & 15,72 \\
\hline Centro-Oeste & 7,29 & 7,35 & 7,26 \\
\hline \multicolumn{4}{|l|}{ Situação dos domicílios } \\
\hline Urbanos & 86,84 & 84,20 & 86,86 \\
\hline Rurais & 13,16 & 15,80 & 13,14 \\
\hline \multicolumn{4}{|l|}{ Faixas etárias } \\
\hline De 15 a 25 anos & 28,32 & 33,55 & 28,29 \\
\hline De 26 a 35 anos & 32,84 & 30,32 & 32,85 \\
\hline De 36 a 49 anos & 38,84 & 36,13 & 38,86 \\
\hline \multicolumn{4}{|l|}{ Anos de estudo } \\
\hline Até 5 anos & 22,74 & 25,38 & 22,76 \\
\hline De 6 a 10 anos & 31,76 & 34,99 & 31,77 \\
\hline 11 anos ou mais & 45,50 & 39,64 & 45,48 \\
\hline \multicolumn{4}{|l|}{ Cor } \\
\hline Branca & 40,53 & 39,87 & 40,53 \\
\hline Preta & 10,64 & 10,16 & 10,64 \\
\hline Parda & 43,82 & 44,76 & 43,83 \\
\hline Amarela & 3,34 & 3,41 & 3,33 \\
\hline Indígena & 1,67 & 1,79 & 1,67 \\
\hline \multicolumn{4}{|l|}{ Estado conjugal } \\
\hline Com cônjuge & 67,40 & 68,74 & 67,40 \\
\hline Sem cônjuge & 32,60 & 31,26 & 32,60 \\
\hline \multicolumn{4}{|l|}{ Trabalho } \\
\hline Com trabalho & 84,82 & 59,25 & 84,83 \\
\hline Sem trabalho & 15,18 & 40,75 & 15,17 \\
\hline \multicolumn{4}{|c|}{$\begin{array}{l}\text { Faixas de renda domiciliar mensal per capita } \\
\text { (em salários mínimos de 2006) }\end{array}$} \\
\hline Até $1 / 2$ SM & 6,76 & 7,58 & 6,76 \\
\hline Mais de $1 / 2$ a 1 SM & 12,64 & 16,09 & 12,64 \\
\hline Mais de 1 a 2 SM & 23,51 & 24,61 & 23,48 \\
\hline Mais de 2 a 3 SM & 18,55 & 16,90 & 18,57 \\
\hline Mais de 3 a 5 SM & 15,78 & 14,06 & 15,78 \\
\hline Mais de 5 a 10 SM & 15,70 & 14,20 & 15,71 \\
\hline Mais de 10 a 20 SM & 5,51 & 5,03 & 5,52 \\
\hline Mais de 20 SM & 1,55 & 1,52 & 1,55 \\
\hline
\end{tabular}


(Continuação)

\begin{tabular}{|c|c|c|c|}
\hline \multirow{2}{*}{ Atributos } & \multicolumn{2}{|c|}{ Amostra total } & \multirow{2}{*}{$\begin{array}{c}\begin{array}{c}\text { Amostra } \\
\text { balanceada }\end{array} \\
\text { ED e PCRS }\end{array}$} \\
\hline & ED & PCRS & \\
\hline \multicolumn{4}{|l|}{ Religião } \\
\hline Católica & 60,64 & 61,35 & 60,63 \\
\hline Evangélica & 25,37 & 25,16 & 25,38 \\
\hline Outras & 6,78 & 5,81 & 6,79 \\
\hline Nenhuma & 7,21 & 7,68 & 7,21 \\
\hline \multicolumn{4}{|l|}{ Programa Bolsa Família (PBF) } \\
\hline Beneficiárias & 17,83 & 19,70 & 17,84 \\
\hline Não beneficiárias & 82,17 & 80,30 & 82,16 \\
\hline Observações & 7.824 & 12.003 & 7.809 \\
\hline População (amostra expandida) & 26.995 .962 & 40.395 .712 & 26.970 .420 \\
\hline
\end{tabular}

Fonte: PNDS de 2006. Elaboração dos autores. 